\title{
SSinteza
}

Impact of Internet on Business Activities in Serbia and Worldwide

Uticaj Interneta na poslovanje u Srbiji i svetu

DOI: 10.15308/SINTEZA-2014-446-449

\section{ZA KRITIČKU I PROAKTIVNU UPOTREBU INTERNETA: ZNAČAJ PRAKTIKOVANJA MEDIJSKOG OBRAZOVANJA}

\author{
Mirjana M. Kristović \\ Filozofski fakultet Univerziteta u Nišu, Srbija
}

\begin{abstract}
:
Kompleksnost i višeznačnost relacije na koju referiše jedna od podtema ove konferencije "internet i obrazovanje" implicira i omogućava različite konkretizacije njenog razmatranja. Tako se za brojne naučnike i pedagoge ova očituje kroz/kao razmatranje pitanja INTERNET U OBRAZOVANJU, to jest kao pitanje njegove instrumentalne funkcije, u svrhu sticanja (proširivanja) znanja. Drugi, pak, naznačenu temu recipiraju u značenju OBRAZOVANJE ZA INTERNET, što će reći kao osposobljavanje za njegovo kritičko i proaktivno korišćenje, ne samo. ali svakako i u nastavi, a što jeste funkcija medijskog obrazovanja.

Polazeći od pomenutog tretiranja medijskog obrazovanja, u ovom radu predočavaju se teorijske elaboracije o njegovoj suštini i svrsi uopšte, a posebno u smislu njegovog doprinosa razvijanju svesti o, kako pozitivnim tako i negativnim, posledicama primene interneta, pre svega u nastavi.
\end{abstract}

\section{Key words:}

medijsko obrazovanje, internet, razvijanje kritičke svesti, sticanje znanja.

\section{UVOD}

U današnje vreme sve je zastupljeniji diskurs o medijatizaciji društvenog života, i to kao o procesu koji neprestano dobija na intenzitetu i postaje sveobuhvatan, što će reći da mediji - „tradicionalni“, ali i „novi“, štaviše, drugi uveliko zadobijaju prednost nad prvim - „zaposedaju“ sve sfere ljudskog delovanja, izazivajući (iziskujući) bitne promene u načinu njihovog osmišljavanja, usmeravanja i objektiviranja. Što se tiče "novih" medija, plauzibilno je predočavanje da internetu pripada posebno mesto, $s$ obzirom da se ispostavlja da ovaj „moćno utiče na gotovo sve aspekte našeg sveta, od trgovine do obrazovanja." (Turan, Tinmaz, Goktaz, 2013:138) Ako je reč o potonjoj sferi društvene prakse, utoliko što primena interneta u nastavi jeste, istovremeno, imperativ, pretpostavka i indikator njenog osavremenjivanja, ali i svojevrstan izazov za njene aktere, pitanje čije postavljanje biva neizbežno i neophodno tiče se potrebe i značaja objektivnog, svestranog i kompetentnog domišljanja različitih aspekata korišćenja ovog medija kao nastavnog sredstva - ne samo, ali pre svega kao izvora informacija koje će učenicima služiti za ovladavanje školskim gradivom, a što jeste funkcija medijskog obrazovanja. To je perspektiva iz koje se u ovom

\section{OSVRT NA POIMANJA SUŠTINE I SVRHE MEDIJSKOG OBRAZOVANJA}

Danas je medijsko obrazovanje u mnogim zemljama širom sveta prepoznato i prihvaćeno kao bitan segment obrazovne delatnosti. Mada se mogu zapaziti manje ili veće razlike koje se, pre svega, tiču opredeljenja za određeni koncept medijskog obrazovanja, $\mathrm{u}$ okviru nacionalnih obrazovnih podsistema (Erjavec, 2005), evidentna je generalna saglasnost oko potrebe i značaja njegovog implementiranja.

Što se tiče različitih koncepata medijskog obrazovanja, valja napomenuti da se njihovo distingiviranje može obavljati po različitim osnovama, što sugeriše zaključak da samim tim i njihovo elaboriranje iziskuje da bude predmet posebnog naučnog angažmana. Stoga će se ovde ostati kod naznačavanja koncepata za koje se nalazi da tangiraju temu koja je u ovom radu u fokusu interesovanja. Ustvari, u pitanju su dva koncepta za koje je osnovano reći da su, u određenom smislu, kompatibilni, ali i da su, upravo stoga, oba podložna kritičkom promišljanju. Prvi od njih poistovećuje medijsko obrazovanje sa obučavanjem za korišćenje medija kao nastavnog sredstva, tojest ove tretira isključivo kao obrazovnu tehnologiju, sagledava ih kroz njihovu instrumentalnu upotrebu. Artikulisa- 
nje drugog koncepta takođe reflektuje potenciranje medija kao tehnologije, štaviše, fasciniranost njenim savremenim dostignućima. Saobrazno tome, sticanje informacione pismenosti biva, ne samo osnovna, nego i jedina svrha medijskog obrazovanja. Time nastaje opasnost (što, u osnovi, važi i za prethodno naznačeni koncept) od redukovanja medijskog obrazovanja „na formu tehničkog treninga pri čemu bi kritička dimenzija medijske teorije bila izgubljena," (Frau-Meigs, 2004:20)

Utoliko, ovakva konceptualizacija medijskog obrazovanja teško da može respondirati njegovom poimanju kao činioca razvoja demokratskog društva, a što će ono biti u meri u kojoj doprinosi podsticanju građana na uviđanje i prihvatanje značaja sopstvenog kritičkog, proaktivnog odnosa prema medijima. Preduslov, pak, za formiranje takvog odnosa je upućivanje u društvene agense njihovog nastajanja i delovanja. Pri tome bi se podrazumevalo njihovo sagledavanje, „kao tehničkih tvorevina i kao društvenih institucija“ (Kristović, 2013) - tojest, kao „mesta“ proizvođenja dobara koja su u funkciji zadovoljavanja određenih društvenih potreba, naravno, kroz međusobnu povezanost ove dve odredbe.

Shodno ovakvom poimanju medijskog obrazovanja, njegov najveći značaj je u tome što ljude upućuje na „postavljanje pravih pitanja" prilikom komuniciranja različitih vrsta medijskog sadržaja (korišćenja svake od medijskih tehnologija), što bi vodilo do „razumevanja posledica izloženosti medijima (Zgrabljić-Rotar, 2005:27) i doprinosilo sprečavanju (izbegavanju) onih negativnih, ili, kako bi to Poter formulisao $(2011,126)$, orijentisanju na „proaktivno rešavanje problema potencijalnih rizika."

\section{OBRAZOVANJE ZA INTERNET}

Internet je uveliko prisutan u životu savremenog čoveka; gotovo da nema sfere društvenog života u kojoj se ne očituje njegov moćni uticaj na način usmeravanja, obavljanja i postignuća ljudskih - grupnih i individualnih delatnosti. S tim u vezi, osnovano se ukazuje da pojavom i upotrebom interneta nastaju brojne, do skora neslućene, mogućnosti realizovanja raznovrsnih društvenih potreba, ali, takođe, problemi i dileme, u pogledu posledica njegove upotrebe. Ovakav kritički i kompleksan pristup pokazuje se generalno legitimnim, što bi značilo u odnosu na sve oblasti primene ovog dostignuća razvoja informacionokomunikacione tehnologije (pri čemu se podrazumeva da, utoliko što se radi o različitim oblastima, prihvatanje pomenutog pristupa kao opšte važećeg ne znači i uniformnost u pogledu njegove aplikacije).

Intenzitet kojim se omasovljuje populacija korisnika interneta s pravom se može smatrati impresivnim. Znatan deo te populacije čine mladi ljudi, predškolskog i školskog uzrasta. Njima je internet posebno prijemčiv, prihhvataju ga kao nešto što im je „blisko“, „prisno“, spretnost koju manifestuju prilikom njegove upotrebe može stvarati utisak da se radi o spretnosti kao „urođenoj sposobnosti“. Ovome svakako doprinosi to što veoma rano dolaze u kontakt sa internetom, odnosno kompjuterom, uz njih odrastaju (Turan, Tinmaz i Gogtaz, 2013); dobijaju mogućnost da im svakodnevno pristupaju i tu moguć- nost koriste u meri i na način koji ih čine neizbežnim, sveprisutnim, dominantnim činiocem njihovih svekolikih aktivnosti. Naznačena napomena je, dakako, po sebi relevantna, ali, ona, takođe, kao što će se kasnije pokazati, tangira pitanje čijim se promišljanjem ovaj rad bavi. Isto, pak, važi i za predočavanje onoga što je mnogo puta (kroz brojna istraživanja) potvrđeno, a tiče se dominantne svrhe upotrebe interneta od strane dece i omladine. Naime, njemu se prevashodno, ako ne i isključivo, pristupa da bi se ostvarila potreba za zabavom. Osnovni problem, međutim, nije ovo opredeljenje kao takvo, nego posledice koje otuda proishode. Konkretnije rečeno, obe napomene instruktivne su za razmatranje potrebe i značaja implementiranja medijskog, u ovom slučaju, obrazovanja za kritičko, kompetentno i proaktivno korišćenje interneta. To se odnosi na sva područja društvene prakse, ali ovom prilikom akcenat će biti stavljen na područje institucionalnog sticanja i usvajanja znanja, tojest na primenu interneta u nastavi.

Jedan od imperativa modernizacije nastavnog procesa (razume se, u svim segmentima školskog sistema), ali i pokazatelja njenih dometa, jeste primena "novih“ medija u realizovanju ovog procesa. To imlicira da se radi o stvaranju pretpostavki za njegovo unapređivanje, dosezanja višeg kvaliteta njegovog praktikovanja, uvećavanja mogućnosti pribavljanja informacija (sticanja znanja), referentnih za određene nastavne discipline. Što se tiče interneta, premda njegova komunikaciona funkcija danas postaje sve izraženija (Fuchs, 2013), njegova informativna funkcija ne gubi na značaju - naprotiv, internet kao sredstvo pribavljanja informacija, sticanja znanja, sve više je u upotrebi, upravo u institucijama kojima je ovo primarna i imanentna delatnost, što će reći u obrazovnim institucijama..

Do sada je mnogo pisano o novim mogućnostima i pozitivnim posledicama primene interneta u nastavi. Tako se, na primer, ističe mogućnost raspolaganja i korišćenja „mnogo više načina za pronalaženje,... mnogobrojnih formi pristupanja sadržaju“. Takođe: „Mnogo ljudi može kontaktirati isti sadržaj u isto vreme. Selektovani delovi mogu biti korišćeni u sekvencama i u vreme koje pojedincu odgovara." (Rice, 2004:129-130) Ako navedena konsideracija ima opšti karakter i značenje, to jest, referiše na određene performanse interneta koje mogu biti instrumentalizovane u svim područjima društvenog života, promišljanje primene interneta u nastavi, $u$ svrhu ovladavanja relevantnim znanjem, upućuje na detektovanje nekih njenih posebnih aspekata.

Tako se napominje da „uvođenje“ interneta u učionicu nužno dovodi do promena, usled kojih se tradicionalni model sprovođenja nastavnog procesa pokazuje prevaziđenim. Ovo pre svega ili posebno, ako se imaju u vidu uloge oba subjekta ovog procesa, tojest njihov međusobni odnos. Učenici postaju njegovi aktivni akteri - u smislu da više nisu (isključivo) usmereni na svoje nastavnike, kao prenosioce znanja, već za njime samostalno tragaju. Samostalno, a što znači bez kontrole nastavnika (kao ni roditelja - uostalom, ovo važi i za sve druge slučajeve u kojima se deca i omladina pojavljuju kao korisnici interneta). Da li time osvajaju slobodu, u jednom bitnom segmentu svoje 
aktivnosti? Mnogi autori skloni su potvrdnom odgovoru i to na neupitan način. Međutim, ako učenici imaju slobodu u ,odnosu na nastavnike, u pronalaženju i odabiru sadržaja koji (bi trebalo da) služi ispunjavanju školskih zadataka, da li je ova neograničena, da li, kao takva, zaslužuje bezuslovno odobravanje? „Internet dopušta učenicima određeni stepen slobode. Doduše, izgleda da je ta sloboda ograničena silama na koje nailaze na internetu. Njima nisu izloženi onako direktno, kako je to u slučaju nastavnikove kontrole u učionici, tako da njih nije lako prepoznati." (Rye, 2013:35) Ali, utoliko ništa manje od neposredne kontrole nastavnika limitiraju slobodu učenika, čak bi se moglo reći - naprotiv.

Radi se o silama (moći) koje se ponekad percipiraju kao samosvojne, tojest $\mathrm{u}$ smislu da ih poseduju „nehumana tela" koja deluju nezavisno od ljudske volje. U tom kontekstu se, na primer, napominje da „Google i njegov algoritam uglavnom determinišu kako se učenici povezuju sa digitalnim protokom informacija“, odnosno da „svičeri“ „imaju kapacitet da određuju koja vrsta informacija će biti protočna, kada i u kom formatu." (isto: 38) Bez ulaženja u podrobnije, kritičko razmatranje ovakvog diskursa o moći koja se pripisuje tehnologiji, na ovom mestu samo će se napomenuti da ta moć, ipak, nije nešto što se samogeneriše, odnosno da i ona, zapravo, predstavlja rezultat nekih ideja, odluka i angažmana određenih pojedinaca - pripadnika ljudskog društva.

Osamostaljivanje učenika u pogledu prikupljanja znanja koja treba da budu u funkciji ovladavanja nastavnim gradivom, ne znači njihovo prepuštanje samima sebi u obavljanju ove aktivnosti. Uloga nastavnika ne gubi na značaju, nego podrazumeva (iziskuje) transformisanje: uloga kontrolora menja se u ulogu aktera osposobljavanja učenika za kritičko, kompetentno i proaktivno korišćenje interneta, u cilju dosezanja kvalitetnije nastave i postizanja što boljih i efektnijih rezultata procesa učenja. Utoliko što tome (treba) da služi medijsko obrazovanje, nastavnicima biva zadato upućivanje u njegovu svrhu, zadatke, elemente, načine praktikovanja.

Poimanje medijskog obrazovanja kao kompleksnog procesa učenja medija, koji se ne svodi na osposobljavanje za korišćenje medijske tehnologije, nego treba da doprinosi razumevanju medija, njihovog funkcionisanja u sklopu određenog društvenog (ekonomskog, kulturnog ...) konteksta, posebno dobija na značaju u slučaju interneta („novih“ medija) i njegove upotrebe - ne samo, ali svakako i u nastavi. To će reći, naglašavanje opasnosti poistovećivanja (redukovanja) obrazovanja za internet na sticanje odgovarajućih tehničkih znanja i veština, tojest medijske kompetencije na njenu ,instrumentalno kvalifikacijsku dimenziju“ (Bake, 3013), itekako je opravdano. Ukoliko se to dešava (a dešava se, ne samo kod nas), odgovornost, naravno, prevashodno leži na nastavnicima. Opasnost bi se mogla smatrati većom, ukoliko se ima u vidu, a na šta je ranije u ovom tekstu ukazano, „bliskost“ učenika sa novim informaciono-komunikacionim tehnologijama, što je, često, njihova prednost u odnosu na nastavnike. Oni sebe percipiraju kao „medijski mudre“ osobe (Frau-Meigs,ed., 2004), bivaju samozadovoljni tehničkim znanjima i veštinama koja „spontano“ stiču - a takva znanja i veštine smatraju (ukoliko uopšte o tome rezonuju) dovoljnim i za pristupanje internetu i komuniciranje različitih sadržaja koje ovaj nudi.

Ukazivanje na potrebu razvijanja kritičke svesti učenika i osposobljavanja za njeno praktikovanje prilikom korišćenja interneta za prikupljanje informacija, relevantnih za uspešno obavljanje njihovih temeljnih školskih zadataka, jeste osnovano i instruktivno - podjednako s obzirom na njegovo sagledavanje kao tehničkog sredstva, kao i što se tiče sadržaja koji se njime posreduju. Prvo bi impliciralo da se, umesto što će se internet tretirati „zdravo za gotovo“, ispoljavati impresioniranost njegovim tehničkim performansama, uviđa i prihvata da nijedna, pa ni ova tehnologija, nije neutralna, puki alat, da ništa od onoga što je čini ne postoji samo po sebi i za sebe, nezavisno od ljudske intervencije. Napomena koja je, takođe, ranije izložena, tangira pitanje sadržaja. Kao što je već naznačeno, populacija koja se ovde tretira prevashodno je usmerena na sadržaje zabavnog karaktera, dakle, kao i kada se radi sadržajima „tradicionalnih" medija (u prvom redu, televizije). Ako ovo važi za preferencije, šta bi se moglo reći za način recipiranja zabavnih sadržaja koje im se nude na internetu? Zapažanje čija eksplikacija sledi ne samo da, nego itekako važi i u ovom konkretnom slučaju (a odnosi se na tehnologije i kulturne tvorevine koje ljudi njihovim posredstvom komuniciraju): „Većina ljudi odnosiće se prema novim medijskim formama uveliko na isti način kao što se odnose prema starim medijima“. (Croteau, Hoynes, 1997: 322) Odnos prema zabavnim sadržajima na internetu ne razlikuje se od odnosa prema zabavnim sadržajima na televiziji: to je pasivan odnos; puko prepuštanje zabavi, njeno trošenje, kao svake druge vrste robe. Stoga se upućuje na povezanost korišćenja interneta za potrebe nastave sa njegovim koriščenjem u slobodno vreme. (Rye, 2013:37) - potonje se neminovno odražava na prethodno. To, tim pre i više, čini opravdanim i urgentnim angažovanje nastavnika na menjanju ovakvog, dominantnog, odnosa učenika prema internetu, odnosno sadržajima koji im se njime posreduju - ne samo onih koji se tiču nastave, u pravcu njihovog oblikovanja kao kritičkih, proaktivnih korisnika ovog medija. Dakako, nastavnici su ti koji treba da se osposobe za obavljanje ovog zadatka, a što će postići kroz sopstveno medijsko obrazovanje.

\section{ZAKLJUČAK}

Ako primena interneta u nastavi podjednako postaje prihvatljiva (poželjna) i neizbežna,adekvatno pripremanje, obučavanje i osposobljavanje za njegovu primenu obezbeđuje postizanje višeg kvaliteta nastave. Tome služi medijsko obrazovanje koje je u ovom konkretnom slučaju, po svojoj suštini i cilju, obrazovanje za internet.

\section{Zahvalnice}

Originalni naučni rad pripremljen u okviru projekta "Tradicija, modernizacija i nacionalni identitet u Srbiji i na Balkanu u procesu evropskih integracija"(projekat br. 179073) koji realizuje Centar za sociologiju Filozofskof fakulteta Univerziteta u Nišu, a koji finansijski podržava Ministarstvo prosvete i nauke Republike Srbije. 


\section{LITERATURA}

[1] (2004), Media Education - A Kit for Teachers, Students, Parents and Professionals. Divina Frau.Meigs (ed.), UNESCO, Paris

[2] Bake, D. (2013), Medijska pedagogija. Centar za medije i komunikacije, Fakultet za medije i komunikacije, Univerzitet Singidunum, Beograd.

[3] Croteau, D., Hoynes, W. (1997), Media/Society. Industries, Images, and Audiences. Pine Page Press. Thousand Oaks, London, New Delhi.

[4] Erjavec, K. (2005), Odgoj za medije: od koncepta do školske prakse. U Medijska pismenost i civilno društvo. Uredila Nada Zgrabljić-Rotar. 77-107. Medijacentar. Sarajevo.

[5] Fuchs, Ch. (2013), Social Media - A Critical Introductio. Sage. Losa Angeles, London, New Delhi, Singapore, Washington DC.
[6] Kristović, M. „Medijsko obrazovanje i unapređivanje interkulturnog razu,evanja, "Unpublished.

[7] Poter, Dž. (2011), Medijska pismenost. Clio, Beograd.

[8] Rice, R. (2004), Artifacts and Paradoxes in New Media. In McQuail's Reader in Mass Communication Theory. Ed. D.McQuail. Sage Publications. London, Thousand Oaks, New Delhi.

[9] Rye, S.A. (2013), „Conected Youth. Young Students' Extensibility and Use of the Internet to Search for Information", Nordicom Review, Vol34, No.1, pp.13-40, June 2013.

[10] Turan, Z., Tinmaz, H. And Goktaz, Y. (2013), „The Rasons for Non-Use of Social Networking Websites by University Students“, Comunicar - Scientific Journal of Media Education, Vol.XXI, No.41, pp.137-145, 2013.

[11] Zgrabljić-Rotar, N. (2005), Mediji - medijska pismenost, medijski sadržaji i medijski utjecaji. U Medijska pismenost i civilno društvo. Uredila Nada Zgrabljić-Rotar. 9-45. Medijacentar. Sarajevo.

\section{FOR CRITICAL AND PROACTIVE USE OF INTERNET: THE SIGNIFICANCE OF PRACTICING MEDIA EDUCATION}

\begin{abstract}
:
The complexity and multi-meaning of a relation to which one of subtopics of this conference refers - „Internet and education“ implicates and enables different concretization of its consideration. Thus it manifests through/as consideration of question INTERNET IN EDUCATION for numerous scientists and pedagogs, that is a question of its instrumental function, in the purpose of getting (expand) knowledge. The others receipt this subject in the meaning of EDUCATION FOR INTERNET, that is as operating for its critical, proactive use, not only, but certainly ih teaching too, which is the function of media education. Starting from mentioned treatment of media education, in this paper the author visualizes theoretical elaborations on its essence and purpose in general, and especially in the sence of its contribution to the development of conciousness about positive, as well as negative consequences of using internet, in teaching before all.
\end{abstract}

\section{Key words:}

media education, internet, development of critical consciousness, getting of knowledge. 